\title{
Lack of Venodilative Activity of Alpha Human Atrial Natriuretic Polypeptide in Patients with Congestive Heart Failure
}

\author{
Hiroshi Ikenouchi, M.D., Hiroshi Sato, M.D., \\ Yasunobu Hirata, M.D., Masahiko Irzuka, M.D., \\ Takashi Serizawa, M.D., and Tsuneaki Sugimoto, M.D.
}

\section{Summary}

We studied the effect of alpha human atrial natriuretic polypeptide (hANP) on venous vessels by occlusion plethysmography in 7 patients with congestive heart failure. In another 8 patients the effect of nitroglycerin was studied to validate the methodology. Forearm venous pressure (VP) and volume change $(\mathcal{N})$ were measured simultaneously. The relationship between venous pressure and volume change was described by the equation $\mathrm{VP}=\mathrm{C} \times \mathrm{e}^{(\mathbf{K} \times \Delta \mathrm{V})}(\mathrm{r}=0.98 \pm 0.01)$ and the venous stiffness constant $(\mathrm{K})$ was calculated. Alpha human atrial natriuretic polypeptide $(0.1 \mu \mathrm{M} / \mathrm{kg} / \mathrm{min})$ was infused intravenously at a dose sufficient to cause arteriodilation. The pressure-volume curve of the peripheral veins was shifted rightward on the volume axis and the stiffness constant $(\mathrm{K})$ was decreased $(-28.1 \%, \mathrm{p}<0.03)$ significantly by nitroglycerin. Alpha human atrial natriuretic polypeptide significantly decreased systemic vascular resistance but did not shift the pressure-volume curve of the vein nor did it decrease the stiffness constant $(\mathbf{K})$. We conclude that hANP has far less venodilating effect than arteriodilating effect in congestive heart failure patients.

\section{Additional Indexing Words:}

Strain gauge plethysmography

Pressure-volume relation Peripheral circulation Venous tone

T $\mathrm{N}$ patients with heart failure generalized arteriolar and venous constriction is observed.1,2) This vasoconstriction is mediated in part by sympathetic vasoconstrictor impulses. In addition, the concentration of angiotensin II is elevated and contributes to both arterial vasoconstriction and the increase in venous tone. ${ }^{3 / 4)}$ Increased plasma concentrations of vasopressin and prostaglandins may also contribute to an increase in vascular

From the Second Department of Internal Medicine, Faculty of Medicine, University of Tokyo, Tokyo, Japan.

Address for reprints: Hiroshi Ikenouchi, M.D., Second Department of Internal Medicine, Faculty of Medicine, University of Tokyo, 7-3-1 Hongo, Bunkyo-ku, Tokyo 113, Japan.

Received for publication November 29, 1988.

Accepted February 15, 1989. 
tone. ${ }^{11}$ Increased extravascular fluid or edema can also increase tissue pressure and external pressure on the systemic veins.

Alpha human atrial natriuretic polypeptide (hANP) has been shown to cause diuresis and arterial vasodilation in experimental animals ${ }^{5}$-7) and humans. ${ }^{8)}$ Its effect on the veins, however, is still controversial. A venous dilatative effect has been suspected from the observed decrease in cardiac filling pressure..$^{91,101}$ Several reports have suggested that the natriuretic polypeptide has no venodilating activity or that it even may have active venoconstrictive action in rats. ${ }^{11,12)}$ In patients with heart disease, the direct effects of hANP on the venous system have not yet been fully evaluated. We studied the hemodynamic changes and peripheral circulatory reaction following administration of nitroglycerin and alpha hANP in patients with congestive heart failure using strain gauge plethysmography.

\section{Methods}

Subjects: Seven patients ( 4 males and 3 females) with congestive heart failure (mean age: 57 years, range: 40 to 80 ) were studied with alpha human atrial natriuretic polypeptide (hANP). Eight patients ( 5 males, 3 females, one of whom was also in the hANP group), having a mean age of 59 years (range: 44 to 88 ) were studied with nitroglycerin in order to estimate the effectiveness of our plethysmographic method for the evaluation of peripheral circulation, especially venous compliance. Informed consent to participate in this study was obtained from each patient and the study protocol was approved by the Ethical Committee of the Hospital of the University of Tokyo.

The underlying diseases resulting in congestive heart failure and New York Heart Association functional classification are shown in Table I. The duration of heart failure and treatment with conventional drugs were identical in both groups. All diuretics and vasodilating agents were discontinued at least 12 hours prior to the onset of the study.

Hemodynamic measurements: In the hANP group, the patients were placed in the supine position and a balloon thermodilution catheter was inserted via an introducer sheath inserted into the subclavian or internal jugular vein. Cardiac output, pulmonary wedge pressure, pulmonary arterial pressure and right atrial pressure were measured before hANP infusion, 15 and 30 min after the start of hANP administration and 15 and $30 \mathrm{~min}$ after the end of hANP administration. A venous catheter was inserted into a subcutancous vein of the forearm near the strain gauge for continuous pressure monitoring via a transducer (Statham P-50, Gould Inc.) and kept patent 
Table I. The Underlying Heart Diseases and Severity of Congestive Heart Failure of the Patients in Both the Nitroglycerin and Atrial Natriuretic Polypeptide Groups

\begin{tabular}{l|c|c|c}
\hline \multicolumn{1}{c|}{ Underlying Heart Diseases } & hANP & NTG & Total \\
\hline Dilated Cardiomyopathy & 2 & 1 & 3 \\
Ischemic Heart Disease & 2 & 2 & 4 \\
Aortic Regurgitation & 2 & 2 & 4 \\
Mitral Stenosis and/or Regurgitation & 1 & 3 & 4 \\
Total & 7 & 8 & 15 \\
NYHA & & & \\
I & 0 & 2 & 2 \\
II & 3 & 3 & \\
III & 2 & 2 & 3 \\
IV & 2 & 1 & 15 \\
Total & 7 & 8 &
\end{tabular}

$\mathrm{NTG}=$ nitroglycerin $; \mathrm{hANP}=$ human atrial natriuretic polypeptide $; \mathrm{NYHA}=\mathrm{New}$ York Heart Association.

by the infusion of heparinized saline solution $(10 \mathrm{U} / \mathrm{ml})$. Baseline heart rate, blood pressure and hemodynamic parameters were measured twice at $15 \mathrm{~min}$ intervals before the onset of hANP infusion and the stability of the hemodynamic condition of the patient was verified. Baseline forearm blood flow, forearm vascular resistance and venous compliance were measured using a venous occlusion strain gauge technique. ${ }^{13), 14 \text { ! }}$

Protocol: Alpha human atrial natriuretic polypeptide (Suntory Co.) in saline $(20 \mathrm{ml}, 6-10 \mu \mathrm{g} / \mathrm{ml})$ was infused continuously at a constant dose $(0.1 \mu \mathrm{g} / \mathrm{kg} / \mathrm{min})$ for $30 \mathrm{~min}$ by an infusion pump (STG-503, TERUMO Inc.). The total amount of infused saline was less than $40 \mathrm{ml}$. Blood samples for the analysis of hANP content were drawn from the arm opposite to the infusion before baseline plethysmography and at $15 \mathrm{~min}$ intervals from the start of the infusion until $30 \mathrm{~min}$ after the end of infusion.

Forearm plethysmography for forearm blood flow and venous compliance was repeated 15 and $30 \mathrm{~min}$ after the onset of the infusion and 15 and $30 \mathrm{~min}$ after the end of infusion. Serum hANP levels were assayed using a radioimmuno-assay technique. The limit of detection was less than $1 \mathrm{pg} / \mathrm{ml}$ for hANP and the intra- and interassay coefficients of variation were 7.2 and $13.0 \%$, respectively. ${ }^{15}$

Plethysmographic technique: The study was carried out with the subject relaxed in a supine position, with the right or left arm supported at a level above the heart in order to empty the vein. A venous occlusion cuff $(8.5 \times$ $33 \mathrm{~cm}$ ) was placed around the arm just above the elbow. Another pneumatic cuff was placed around the wrist. A silicone strain gauge (SG-24, MEDA- 
SONICS Inc.), $24 \mathrm{~cm}$ in length, was positioned so that it encircled the forearm at its widest part. Any increase in the volume of the limb will stretch the strain gauge. The correlation between the increase in length of the strain gauge and that of the electrical resistance was linear within the extent of the change in this study. The wrist cuff was inflated well above the systolic blood pressure to exclude the circulation to the hand. Volume changes were calculated by a computer (SPG 16, MEDASONICS Inc.) from those of the forearm girth on the assumption that the shape of the cross section of the forearm is constant. These data were monitored and recorded on paper by a monitoring system (Dynascope DS-1100, AO-5001, Fukuda Denshi Inc.) for further analyses. With the recording paper running, the upper arm cuff was rapidly inflated to $40 \mathrm{mmHg}$ until the venous pressure was elevated to over $24 \mathrm{mmHg}$ or until a plateau was formed. The upper arm cuff was then deflated and the tracing was allowed to return to baseline before another flow recording was made. A series of four measurements were used to determine average forearm blood flow and venous compliance. Forearm arterial resistance was calculated from the forearm blood flow and the mean arterial pressure measured in the opposite arm. There was no significant difference between the blood pressures of the right and left arm in any patient. Throughout each study the room temperature was maintained between 23 and 26 degrees centigrade.

Forearm venous compliance was assessed from the pressure-volume relation during each inflation. The change in forearm volume was plotted against the change in forearm venous pressure from 2 to $24 \mathrm{mmHg}$ in $2 \mathrm{mmHg}$ steps, ie., in 12 points.

Heart rate was automatically measured and recorded on the paper and blood pressure was measured by a conventional sphygmomanometer or was monitored continuously with a cannula inserted into a forearm artery via a transducer.

In the nitroglycerin group, plethysmographic measurements were performed without right heart catheterization. One patient who was also in the hANP group had the study performed on the day following the hANP examination. After the baseline measurement of heart rate, blood pressure, forearm blood flow and venous compliance, nitroglycerin ointment $(5 \mathrm{~cm}$, containing about $30 \mathrm{mg}$ of nitroglycerin, VASOLATOR, Sanwa Chemical Lab. Inc.) was applicd to the chest over an arca of about $5 \times 5 \mathrm{~cm}$ and covered with a thin film attached to the skin by surgical tape. After 15 and $30 \mathrm{~min}$, heart rate, blood pressure, forearm blood flow and venous compliance were measured.

Calculation: Forearm blood flow $(\mathrm{ml} / 100 \mathrm{ml} / \mathrm{min})$ was calculated from 


\section{PLETHYSMOGRAM}
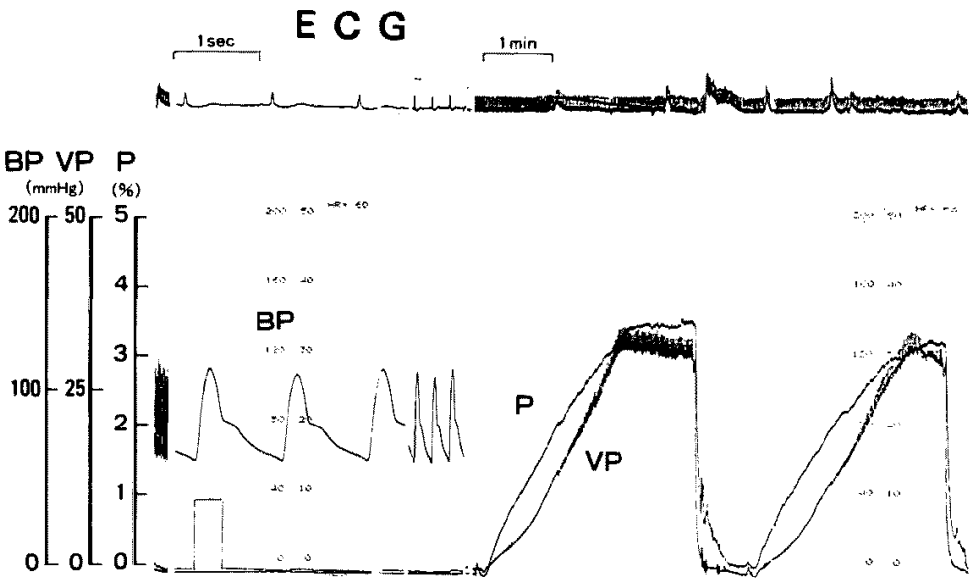

Fig. 1. A recording obtained by the acute occlusion method. The tracing on the left is systemic blood pressure, and those on the right are the responses of venous pressure and volume. $\mathrm{ECG}=$ electrocardiogram; $\mathrm{BP}=$ blood pressure; $\mathbf{V} \mathbf{P}=$ venous pressure; $\mathbf{P}=\%$ change of volume by plethysmography.

the initial slope of the volume change curve (Fig. 1). Forearm vascular resistance was calculated using the formula $\mathrm{FBF}(\mathrm{ml} / 100 \mathrm{ml} / \mathrm{min}) / \mathrm{mBP}$ ( $\mathrm{mmHg}$ ), where FBF is forearm blood flow and $\mathrm{mBP}$ is mean arterial blood pressure. The venous stiffness constant $(\mathbf{K})$ was calculated from the pressure-volume curve by exponential fitting to the equation using 12 points; $\mathrm{VP}=\mathrm{G} \times \mathrm{e}^{\left(\mathrm{K}^{\times} \Delta \mathrm{V}\right)}$, where $\mathrm{VP}$ is venous pressure, $J \mathrm{~V}$ is the change in forearm volume and $\mathrm{C}$ is a constant $(\mathrm{r}=0.98 \pm 0.01)$.

Statistics: All values are presented as means \pm SEM. Differences among all groups were analyzed by one-way analysis of variance followed by a comparison with paired Student's t-test. $\mathrm{P}$ values less than 0.05 were considered to be significant.

\section{RESULTS}

Subjects: The mean NYHA functional class was greater in the hANP group (2.9 in hANP group vs. 2.3 in NTG group, NS). The age and the underlying diseases were similar in both groups (Table I).

Venous tone in the control state: Control pressure-volume curves of all the patients $(n=15)$ were divided into 2 groups, a group with severe congestive heart failure (NYHA III or IV; $n=7$ ) and a group with mild heart 


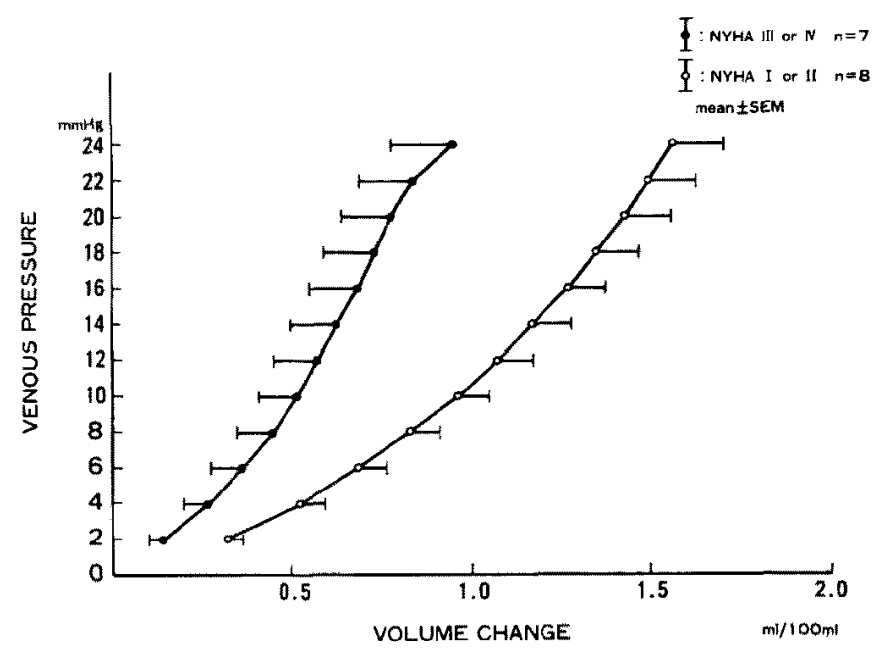

Fig. 2. The relationship between venous pressure and changes in the forearm volume. NYHA $=$ New York Heart Association classification.

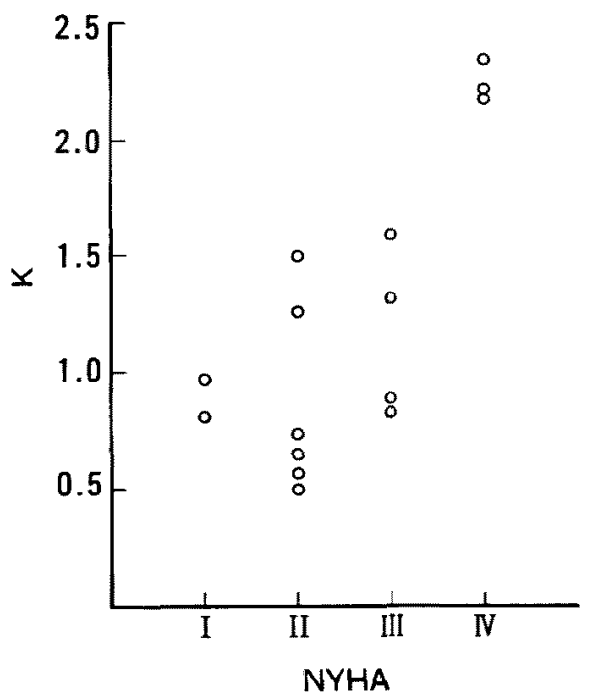

Fig. 3. The relationship between the venous stiffness constant (K) and the New York Heart Association (NYHA) grade.

failure (NYHA I or II; n=8) (Fig. 2). In the severe heart failure patients, a steep elevation of venous pressure was observed when compared with patients with mild heart failure. This was interpreted as meaning that the degree of venoconstriction was related to the severity of the congestive heart failure. The same tendency was seen in the relationship between the NYHA 
Table II. Hemodynamic Changes Produced by Nitroglycerin

\begin{tabular}{c|c|c}
\hline Parameters & Control & NTG \\
\hline HR & $61 \pm 6$ & $65 \pm 7$ \\
SBP & $131 \pm 7$ & $124 \pm 8^{*}$ \\
DBP & $70 \pm 3$ & $69 \pm 4$ \\
MBP & $90 \pm 4$ & $87 \pm 5$ \\
FBF & $1.7 \pm 0.3$ & $2.2 \pm 0.6$ \\
FVR & $73 \pm 22$ & $61 \pm 16$ \\
K & $1.14 \pm 0.2$ & $0.88 \pm 0.2^{*}$ \\
r & $0.970 \pm 0.01$ & $0.976 \pm 0.01$
\end{tabular}

Values are means $\pm \mathrm{SEM} . \quad \mathrm{HR}=$ heart rate (beats/minute); $\mathrm{SBP}=$ systolic blood pressure ( $\mathrm{mmH}$ ); $\mathrm{DBP}=$ diastolic blood pressure; $\mathrm{MBP}=$ mean blood pressure; $\mathrm{FBF}=$ forearm blood flow $(\mathrm{ml} / 100 \mathrm{ml} / \mathrm{min}) ; \mathrm{FVR}=$ forearm vascular resistance $(\mathrm{mmHg} \times 100 \mathrm{ml} \times \mathrm{min} / \mathrm{ml}) ; \mathrm{K}=$ venous stiffness constant; $r=$ correlation coefficient for fitting of the venous stifiness constant. $* p<0.05$ compared with control values.

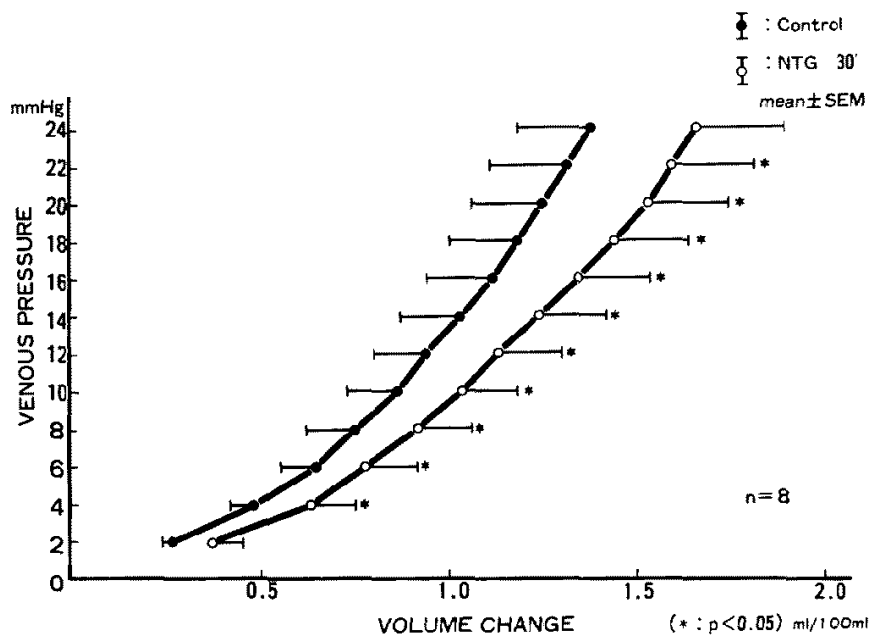

Fig. 4. The relationship between venous pressure and changes in forearm volume. Closed circles indicate the pressure-volume curve in the control state and open circles indicate the curve after nitroglycerin administration. NTG $=$ nitroglycerin. $\quad{ }^{*} \mathrm{p}<0.05$.

classification and the venous stiffness constant K (Fig. 3). Patients with severe congestive heart failure had higher venous stiffness constants,

Nitroglycerin (Table II): Thirty minutes after the nitroglycerin ointment was applied, the hypotensive effect was maximal. Systolic blood pressure was significantly decreased $(131 \pm 7$ to $124 \pm 8 \mathrm{mmHg} ; \mathrm{p}<0.03)$, and heart rate was unchanged ( $61 \pm 6$ to $65 \pm 7$ beats $/ \mathrm{min}$ ). Forearm blood flow 


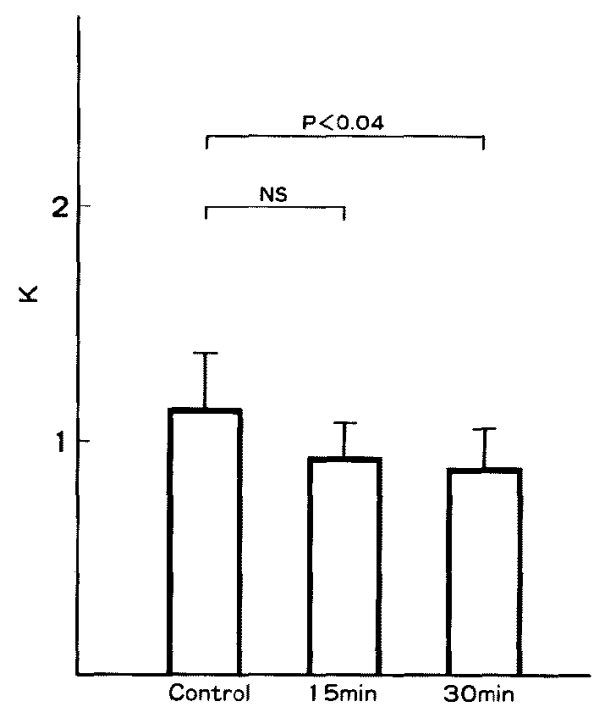

Fig. 5. Changes in the venous stiffness constant (K) 15 and $30 \mathrm{~min}$ after nitroglycerin ointment administration.

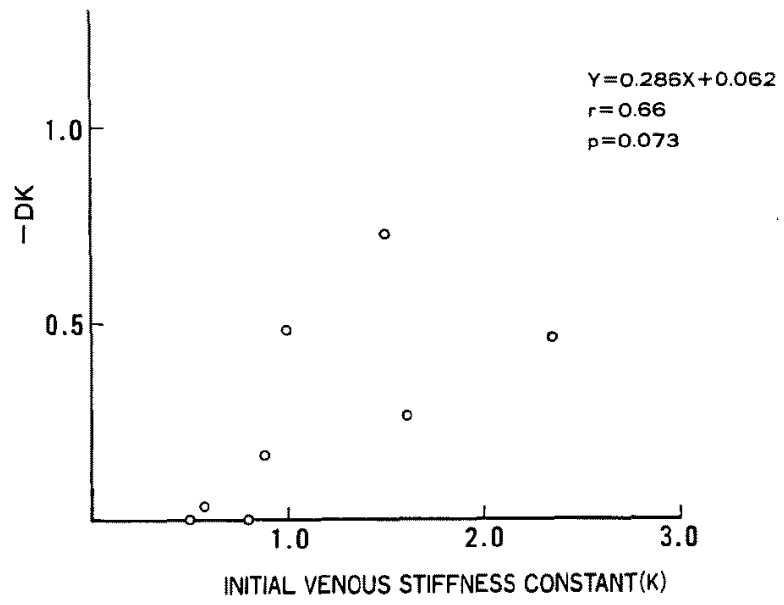

Fig. 6. The relationship between the change caused by nitroglycerin and the initial values of the venous stiffness constant. $-\mathrm{DK}=$ absolute value of change of the venous stiffness constant by nitroglycerin.

was slightly increased $(1.7 \pm 0.3$ to $2.2 \pm 0.6 \mathrm{ml} / 100 \mathrm{~g} / \mathrm{min}, \mathrm{NS})$ while forearm vascular resistance was slightly decreased $(73 \pm 22$ to $61 \pm 16 \mathrm{mmHg} \times 100 \mathrm{ml} \times$ $\mathrm{min} / \mathrm{ml}$, NS), neither being significant (Table II).

The pressure-volume curve was shifted to the right on the volume axis by nitroglycerin (Fig. 4). The venous stiffness constant $\mathrm{K}$ was significantly 
Table III. Hemodynamic Changes Following Administration of Alpha Human Atrial Natriuretic Polypeptide

\begin{tabular}{l|c|cc|cc}
\hline \multirow{2}{*}{ Parameters } & Control & \multicolumn{2}{|c|}{ During infusion } & \multicolumn{2}{c}{ Post-infusion } \\
\cline { 3 - 6 } & & $15 \mathrm{~min}$ & $30 \mathrm{~min}$ & $45 \mathrm{~min}$ & $60 \mathrm{~min}$ \\
\hline HR & $98 \pm 8$ & $100 \pm 7$ & $97 \pm 7$ & $97 \pm 8$ & $93 \pm 7$ \\
SBP & $156 \pm 7$ & $141 \pm 12^{*}$ & $144 \pm 8^{* *}$ & $148 \pm 9^{*}$ & $157 \pm 5$ \\
DBP & $84 \pm 5$ & $78 \pm 7$ & $79 \pm 5$ & $78 \pm 4$ & $80 \pm 5$ \\
MBP & $109 \pm 4$ & $100 \pm 8$ & $101 \pm 4 * *$ & $100 \pm 4^{* *}$ & $106 \pm 4^{* *}$ \\
SPAP & $39 \pm 5$ & $35 \pm 6$ & $34 \pm 6$ & $32 \pm 6^{*}$ & $33 \pm 7$ \\
DPAP & $23 \pm 5$ & $20 \pm 5$ & $20 \pm 4$ & $19 \pm 4$ & $20 \pm 5$ \\
MPAP & $29 \pm 5$ & $25 \pm 5$ & $25 \pm 5$ & $24 \pm 5$ & $25 \pm 6$ \\
PCWP & $16 \pm 4$ & $13 \pm 3$ & $13 \pm 4$ & $13 \pm 4^{*}$ & $13 \pm 4$ \\
RAP & $10 \pm 4$ & $8 \pm 4$ & $7 \pm 4$ & $7 \pm 3$ & $8 \pm 4$ \\
CI & $2.7 \pm 0.3$ & $3.0 \pm 0.3 *$ & $2.8 \pm 0.3$ & $2.6 \pm 0.3$ & $2.5 \pm 0.3$ \\
SVR & $1984 \pm 278$ & $1618 \pm 212^{*}$ & $1696 \pm 193$ & $1820 \pm 57$ & $2073 \pm 296$ \\
PVR & $310 \pm 72$ & $259 \pm 59$ & $251 \pm 63$ & $224 \pm 57$ & $200 \pm 39$ \\
FBF & $2.1 \pm 0.5$ & $1.9 \pm 0.4$ & $2.0 \pm 0.5$ & $1.8 \pm 0.4$ & $1.6 \pm 0.5$ \\
FVR & $74 \pm 16$ & $66 \pm 15$ & $62 \pm 12$ & $70 \pm 14$ & $84 \pm 13$ \\
K & $1.29 \pm 0.2$ & $1.27 \pm 0.3$ & $1.61 \pm 0.4$ & $1.39 \pm 0.3$ & $1.72 \pm 0.5$ \\
r & $0.979 \pm 0.01$ & $0.972 \pm 0.01$ & $0.973 \pm 0.01$ & $0.968 \pm 0.01$ & $0.961 \pm 0.01$ \\
hANP & $926 \pm 424$ & $2892 \pm 146$ & $2941 \pm 186$ & $1238 \pm 463$ & $884 \pm 368$ \\
& & & & &
\end{tabular}

Values are means $\pm S E M . \quad H R=$ heart rate (beats/minute); $S B P=$ systolic blood pressure $(\mathrm{mmHg}) ; \mathrm{DBP}=$ diastolic blood pressure ; $\mathrm{MBP}=$ mean blood pressure ; SPAP = systolic pulmonary arterial pressure ; DPAP = diastolic pulmonary arterial pressure ; MPAP $=$ mean pulmonary arterial pressure; $\mathrm{PCWP}=$ pulmonary capillary wedge pressure ; $\mathrm{RAP}=$ right atrial pressure ; $\mathrm{CI}=$ cardiac index $\left(\mathrm{L} / \mathrm{min} / \mathrm{m}^{2}\right) ; \quad \mathrm{SVR}=$ systemic vascular resistance $\left(\mathrm{dyne} / \mathrm{sec} / \mathrm{cm}^{5}\right) ; \quad \mathrm{PVR}=$ pulmonary vascular resistance; $\mathrm{FBF}=$ forearm blood flow $(\mathrm{ml} / 100 \mathrm{ml} / \mathrm{min}) ; \mathrm{FVR}=$ forearm vascular resistance $(\mathrm{mmHg} \times$ $100 \mathrm{ml} \times \min / \mathrm{ml}) ; K=$ venous stiffness constant ; $r=$ correlation coefficient for the fitting of the venous stiffness constant; hANP $=$ human atrial natriuretic polypeptide $(\mathrm{pg} / \mathrm{ml}) . \quad * \mathrm{p}<0.05, * * \mathrm{p}<0.01$ compared with control values.

decreased $30 \mathrm{~min}$ after nitroglycerin administration $(1.14 \pm 0.2$ to $0.88 \pm 0.2$; $\mathrm{p}<0.04$ ) (Fig. 5). These changes are interpreted as demonstrating that the constant $\mathrm{K}$ decreases with nitroglycerin-induced venodilatation. The extent of venodilatation produced by nitroglycerin was related to the initial venous stiffness constant, ie., the venodilating effect of nitroglycerin was related to the degree of the initial venoconstriction although the linear regression was not significant $(\mathrm{p}<0.07)$. There is a tendency that the more severely the vein was constricted in the control state, the more it was dilated by nitroglycerin (Fig. 6). Therefore, in patients with the mildest degree of heart failure, the veins were very compliant and nitroglycerin had only a minimal venodilatory effect.

Alpha human atrial natriuretic polypeptide (Table III): Systolic blood 


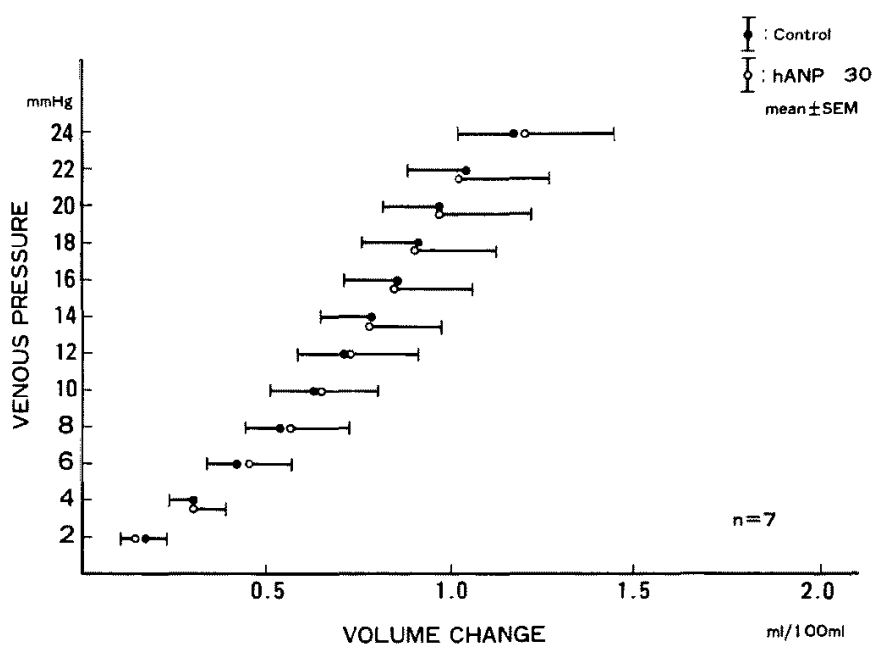

Fig. 7. The relationship between venous pressure and forearm volume change. Closed circles indicate the pressure-volume curve in the control state while open circles indicate that after atrial natriuretic polypeptide administration. hANP $=$ human atrial natriuretic polypeptide.

pressure was decreased significantly $15 \mathrm{~min}$ after the onset of the infusion, and the decrease was sustained for $15 \mathrm{~min}$ after the end of infusion. Heart rate did not change. The cardiac index was increased $15 \mathrm{~min}$ after the onset of infusion. Systolic pulmonary arterial pressure was not decreased significantly during the infusion of hANP, although it was decreased significantly $15 \mathrm{~min}$ after the finish of infusion. Pulmonary capillary wedge pressure was also decreased significantly after the infusion was stopped. Right atrial pressure was slightly decreased, although the change was not statistically significant. The calculated systemic vascular resistance was significantly decreased $15 \mathrm{~min}$ after the administration. Pulmonary vascular resistance was not significantly altered.

The basal plasma concentration of hANP was elevated above the normal level. The concentration was greatly elevated $15 \mathrm{~min}$ after the onset of infusion, to approximately $40 \times$ greater than normal, and then rapidly decreased after the finish of infusion.

Forearm blood flow and forearm vascular resistance were slightly decreased, although the changes were not significant. The venous pressurevolume curve was not shifted (Fig. 7). The stiffness constant $\mathrm{K}$ was calculated with a good fit to an exponential curve $(r=0.97 \pm 0.01)$ and it was elevated slightly after $30 \mathrm{~min}$, although this change was also insignificant (Fig. 8). 


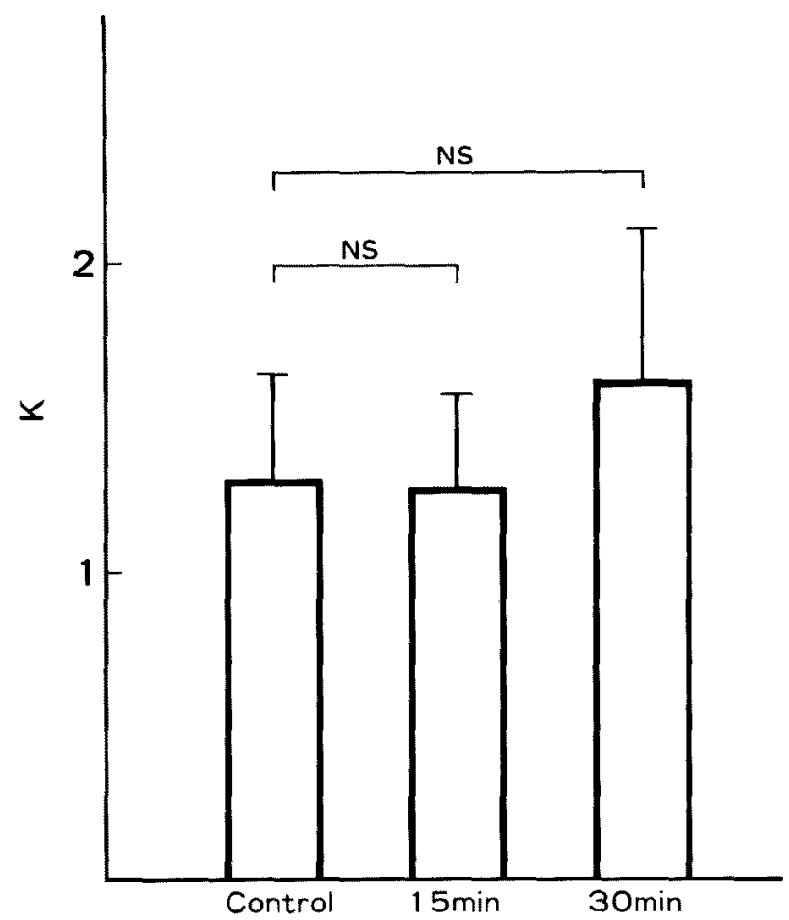

Fig. 8. Changes in the venous stiffness constant $(\mathrm{K}) 15$ and $30 \mathrm{~min}$ after atrial natriuretic polypeptide administration.

\section{Discussion}

Subjects: The two agents were not compared in the same patients except in one case and the severity of heart failure according to the New York Heart Association classification was not identical in the 2 groups. This difference, however, does not affect the conclusion of this study. Venoconstriction and the response to nitroglycerin are greater in more severely ill patients. The response was smaller in the polypeptide group in which the severity of heart failure was greater and veins were expected to be more tonic and sensitive to vasodilating drugs than those in the nitroglycerin group. Therefore, the venodilative effect of hANP was considered to be very weak compared with its arteriodilative effect.

Plethysmography: Strain gauge plethysmography using the acute occlusion technique is a useful method for evaluating the peripheral circulation, especially venous distensibility. ${ }^{13), 14}$ There are several other methods for the measurement of forearm volume changes. For example, an air or waterfilled plethysmograph, and an isotope labeled erythrocyte technique have 
been used. ${ }^{16)}$ Water plethysmography is a method of direct measurement of forearm volume by enclosing the forearm in a water chamber. ${ }^{171,18}$ ? Theoretically, water plethysmography is the most accurate method. Practically, however, it is rather difficult to obtain stable conditions with this method. Strain gauge plethysmography measures forearm volume changes calculated from the changes in circumference measured by the electronic resistance of the stretched strain gauge. ${ }^{18)}$ Although this method is indirect because it uses an assumption, practically it is rather easy to obtain stable data. Forearm blood flow was calculated from the change in forearm volume during venous occlusion and expressed in $\mathrm{ml}$ per $100 \mathrm{gm}$ tissue per minute. ${ }^{\mathbf{1 4}}$ A linear relationship between the values of forearm blood flow obtained with these two plethysmographic techniques is apparent, and the gauge technique is regarded as a sufficiently reliable method for recording changes in limb volume. ${ }^{18)}$

Plethysmography is a relatively noninvasive and simple technique with which to evaluate venous tone. However, it has several problems. Room temperature affects the venous capacitance, ${ }^{19), 20)}$ and so in our study the room temperature was kept constant during measurements. Secondly, it is possible that the data obtained for the forearm do not represent the tonus of veins throughout the whole body. Thirdly, the compliance of individual veins may not be uniform in the limb, and the time course of volume change for each vein may be different when pressure is applied. Capillary filtration and bone flow can influence the pressurc-volume curve of veins. ${ }^{20}$ A previous study recommended that, in order to exclude these disturbing elements as much as possible, it is desirable to make the measurements at an occlusion pressure of $60 \mathrm{mmHg}{ }^{20}$ ) An inflated cuff pressure of $60 \mathrm{mmHg}$ was used in the present study.

In previous studies, venous compliance was evaluated by the pressurevolume curve or forearm volume at a cuff pressure of $30 \mathrm{mmHg}{ }^{14}$ ) The pressure volume curve gives visual information of compliance but not quantitative data. Forearm volume at a cuff pressure of $30 \mathrm{mmHg}$ quantifies the venous compliance but it depicts only one point of the whole pressurevolume relation. Then, we proposed a venous stiffness constant, $\mathrm{K}$, to quantify and simplify the distensibility of veins characterizing the whole pressure-volume relation. As the pressure-volume curve of veins was not linear (Figs. 3, 5 and 8), we fitted it to an exponential curve and obtained favorable results $(r=0.98 \pm 0.01)$. This constant, we believe, expresses the pressure-volume relation of veins and their stiffness very well (Fig. 4). The basal venous tone was related to the degree of heart failure (Figs. 3 and 4). In severe heart failure patients, a steep increment of venous pressure was 
observed compared to patients with relatively mild heart failure (Fig. 3).

Nitroglycerin: Many studies have reported the venodilating effect of nitroglycerin. ${ }^{24), 161,211}$ It is well established that this drug has a marked venodilating effect and a mild arteriolar dilating effect. Sundberg et al ${ }^{19}$ ) reported that a transdermal nitroglyccrin patch increased skin blood flow by $25 \%$ for 20 hours in 15 healthy volunteers. Mason et al ${ }^{14)}$ reported that nitroglycerin administered sublingually increased forearm blood flow, decreased forearm vascular resistance by an average of $35 \%$ of the control values, and decreased venous tone by an average of $19 \%$. In our study, the effect of nitroglycerin ointment was maximal $30 \mathrm{~min}$ after application of the ointment. The pressure-volume curve was shifted to the right on the volume axis, and the venous stiffness constant was significantly decreased by $23 \%$ (Figs. 5 and 6). This may indicate that our plethysmographic method is sensitive enough to correctly evaluate the peripheral circulation, especially peripheral venous tone. The degree of venodilatation tended to be positively related to the initial severity of venoconstriction. The more a vein was constricted in the initial state, the more it was dilated by nitroglycerin (Fig. 6).

Atrial natriuretic polypeptide: It has been suggested that the decrease in central venous pressure induced by atrial natriuretic polypeptide is caused by the relaxation of capacitance vessels. This reasoning is based on observations that the polypeptide decreases left and right atrial pressures associated with decreased stroke volume $\mathrm{e}^{6,99,10)}$ and that it relaxes vascular smooth muscle in vitro. ${ }^{22)-24}$ In anesthetized animals, administration of the polypeptide decreases blood pressure, left ventricular end-diastolic pressure and renal vascular resistance, and increases urine sodium output, blood hematocrit, the glomerular filtration rate, and the filtration fraction. ${ }^{25)-27}$ ) Trippodo et $\mathrm{al}^{12}$ reported in their experiment that the atrial natriuretic polypeptide-induced decrease in central venous pressure in anephric rats can be explained by increased resistance to venous return.

We studied the effect of hANP on the peripheral circulation and determined that the peptide has no venodilating effect on the peripheral veins of the forearm in the dose at which it showed a clear arteriodilative action (Figs. 7 and 8 ).

In 2 patients (NYHA classes II and III), the peptide increased the venous stiffness constant. The venoconstricting response might be a reflex via baroreceptors. ${ }^{14}$ ) No veins of any patient were dilated by hANP in this study.

We used a single dose of hANP and did not obtain a dose-response relationship. Thus, our results should be interpreted as showing that the polypeptide has no venodilating effect at the commonly used dose which 
clearly demonstrated other actions such as arterial dilatation, lowering of left ventricular filling pressure and diuresis.

These results only reflect the effect of the peptide on forearm vessels. We have no information for vessels of other organs.

Clinical implications: Alpha human atrial natriuretic polypeptide has been offered as a promising compensating factor for the pathophysiologic derangements of congestive heart failure due to its arterial dilatation and diuretic actions. However, hANP has no beneficial effect on excessive venoconstriction in patients with congestive heart failure, as shown in this study.

\section{REFERENCES}

1. Abboud FM, Heistad DD, Mark AL, Schmid PG: Reflex control of the peripheral circulation. Progr Cardiovase Dis 18: 371, 1976

2. Zelis R, Nellis SH, Longhurst J, Lee G, Mason DT: Abnormalities in the regional circulations accompanying congestive heart failure. Progr Cardiovasc Dis 18: 181, 1975

3. Curtiss C, Cohn JN, Vrobel T, Franciosa JA: Role of the renin-angiotensin system in the systemic vasoconstriction of chronic congestive heart failure. Circulation 58: 763, 1978

4. Thomas JA, Marks BH: Plasma norepinephrine in congestive heart failure. Am J Cardiol 41: 233,1978

5. Ackerman U, Irizawa TG, Milojevic S, Sonnenberg H: Cardiovascular effects of atrial extracts in anesthetized rats. Can J Physiol Pharmacol 62: 819, 1984

6. Hirata $Y$, Ishii M, Sugimoto $T$, Matsuoka H, Sugimoto T, Kangawa K, Matsuo $\mathbf{H}$ : The effects of human atrial 28-amino acid peptide on systemic and renal hemodynamics in anesthetized rats. Circ Res 57: 634, 1985

7. Fujioka J, Tamaki T, Fukui K, Okahara T, Abe Y: Effects of a synthetic human atrial natriuretic polypeptide on regional blood flow in rats. Eur J Pharmacol 109: 301, 1985

8. Saito Y, Nakao K, Nishimura K, Sugawara A, Okumura K, Obata K, Sonoda R, Ban T, Yasue $H$, Imura $H$ : Clinical application of atrial natriuretic polypeptide in patients with congestive heart failure: beneficial effects on left ventricular function. Circulation 76: 115, 1987

9. Breuhaus BA, Saneii HH, Brant MA, Chimoskey JE: Atriopeptin II lowers cardiac output in conscious sheep. Am J Physiol 249: R776, 1985

10. Lappe RW, Smits JFM, Todt JA, Debets JJM, Wendt RL: Failure of atriopeptin II to cause arterial vasodilation in the conscious rat. Circ Res 56: 606, 1985

11. Chien YW, Frohlich ED, Trippodo G: Atrial natriuretic peptide increases resistance to venous return in rats. Am J Physiol 21 : H864, 1987

12. Trippodo NC, Cole FE, Frohlich ED, MacPhee A: Atrial natriuretic peptide decreases circulatory capacitance in areflexic rats. Circ Res 59: 291, 1986

13. Esquivel M, Burns RJ, Ogilvie RI: Gardiovascular cffects of enprofylline and theophyllinc, Clin Pharmacol Ther 39: 395, 1986

14. Mason DT, Braunwald E: The effects of nitroglycerin and amyl nitrite on arteriolar and venous tone in the human forearm. Circulation 32: 755, 1965

15. Hirata $Y$, Ishii M, Matsuoka H, Sugimoto T, Iizuka M, Uchida $Y$, Serizawa T, Sato H, Kohmoto O, Mochizuki T, Sugimoto T, Miyata A, Kangawa K, Matsuo H: Plasma concentrations of $\alpha$-human atrial natriuretic polypeptide and cyclic GMP in patients with heart disease. Am Heart J 113: 1463, 1987 
16. Wood JE, Eckstein JW: A tandem plethysmograph for study of acute responses. J Clin Invest 37: 41, 1985

17. Lindblad LE: Non-invasive teciniques used to monitor peripheral circulatory changes induced by nitroglycerin. Acta Pharmacol Toxicol 59 (suppl VI): 109, 1986

18. Whitney RJ: The measurement of volume changes in human limbs. J Physiol 121: 1, 1953

19. Sundberg S, Castren M: Drug- and temperature-induced changes in peripheral circulation measured by laser-doppler flowmetry and digital-pulse plethysmography. Scand J Clin Lab Invest 46: 359,1986

20. Colardyn F, Hansen M, Clement DL: Values of venous occlusion plethysmography to study venoactive medication in men. Inter Angiol 4: 215, 1985

21. Parker JO: Nitrate therapy in stable angina pectoris. New Eng J Med 316: 1635,1987

22. Cantin M, Genest J: The heart and the atrial natriuretic factor. Endocrin Rev 6: 107, 1985

23. Maack T, Camargo MJF, Kleinert HD, Laragh JH, Atlas SA: Atrial natriuretic factor: Structure and functional properties. Kidney Int 27: 607, 1985

24. Needleman P, Adams SP, Cole BR, Currie MG, Geller DM, Michener ML, Saper GB, Schwartz D, Standaert DG: Atriopeptins as cardiac hormones. Hypertension 7: 469, 1985

25. Maack T, Marion DN, Camargo MJF, Kleinert HD, Laragh JH, Vaughan ED Jr, Atlas SA: Effects of auriculin (atrial natriuretic factor) on blood pressure, renal function, and the reninaldosterone system in dogs. Am J Med 77: 1069, 1984

26. Dunn BR, Ichikawa I, Pfeffer JM, Troy JL, Brenner BM: Renal and systemic hemodynamic effects of synthetic atrial natriuretic peptide in anesthetized rat. Circ Res 59:237, 1986

27. Hintze TH, Currie MG, Needleman P: Atriopeptins: renal-specific vasodilators in conscious dogs. Am J Physiol 248: H587, 1985 